\title{
Rapid diagnosis of nitrogen status in rice based on Fourier transform infrared photoacoustic spectroscopy (FTIR-PAS)
}

\author{
Ke Wu ${ }^{1,2}$, Changwen Du ${ }^{1,2^{*}}$ (D), Fei Ma ${ }^{1}$, Yazhen Shen ${ }^{1}$, Dong Liang ${ }^{1,2}$ and Jianmin Zhou ${ }^{1}$
}

\begin{abstract}
Background: An effective and expeditious approach to assess plant nitrogen status is urgently needed in rice production and management as the conventional chemical methods are laborious and time-consuming.

Results: Fourier transform infrared photoacoustic spectroscopy (FTIR-PAS) was used to record the spectra of rice leaves for the effective diagnosis of nitrogen nutrition status. The band in the wavenumber range of 1680 to $1630 \mathrm{~cm}^{-1}$ was associated with amide I and that from 1570 to $1510 \mathrm{~cm}^{-1}$ with amide II. We attempted to use this information to characterize the nitrogen status in rice plants at different growth stages. The ratio of photoacoustic intensity of amide II to amide I was measured and applied as nitrogen status index, and considering the yields, the ratio showed a positive linear correlation $\left(R^{2}=0.9\right)$ with the total nitrogen of rice leaves. The ratio at the tillering and full panicle stages were more suitable for diagnosis, a ratio of $0.4-0.55$ indicated an adequate nitrogen status, ratios lower than 0.4 indicated a poor nitrogen status; whereas ratios greater than 0.55 indicated excessive nitrogen supply.
\end{abstract}

Conclusion: Our study provides an effective and rapid strategy for nitrogen-supply assessment in rice based on FTIRPAS, which can guide rational fertilization in rice production.

Keywords: FTIR-PAS, Rice leaves, Amides, Nitrogen status diagnosis

\section{Background}

Rice is one of the most common staple food crops in eastern Asia and feeds more than 65\% of the population in China [1]. Nitrogen plays an important role in crop production and has been a critical factor in rice yields and agricultural environments [2, 3]. However, excessive usage of nitrogen fertilizer in rice cultivation is relatively common, which not only increases the production cost but also pollutes the environment $[4,5]$. Therefore, timely and effective measurement of crop nitrogen status is critical for increasing nitrogen use efficiency and reducing environmental degradation $[6,7]$.

Conventional diagnosis methods currently used for measuring nitrogen status in crops are chemical in nature, which are laborious and time-consuming $[8,9]$;

\footnotetext{
*Correspondence: chwdu@issas.ac.cn

${ }^{1}$ The State Key Laboratory of Soil and Sustainable Agriculture, Institute of Soil Science, Chinese Academy of Sciences, Nanjing 210008, China
} Full list of author information is available at the end of the article thus, chemical analysis is not an effective method for efficient crop fertilization management, especially in precision agricultural management. Therefore, an effective and rapid approach to diagnose plant nitrogen status is urgently needed in rice production and fertilization management.

Modern remote sensing technology has been widely used in the estimation of crop biochemical components, including nitrogen $[10,11]$. Most of the remote sensing techniques depend on near-infrared wavelengths. Nowadays, as a promising alternative, Fourier transform infrared photoacoustic spectroscopy (FTIR-PAS) has been effectively applied in many fields, such as analyzing soil physical and chemical properties [12, 13], identification of plant diseases [14], gas monitoring [15], and food safety $[16,17]$. Compared to the near-infrared spectrum, the mid-infrared spectrum provides more information about the measured targets [18-20]. From the scattering of plant tissue [21], photoacoustic spectroscopy can 
capture more information from leaves due to the depthprofiling abilities, and then assess the nutritional status of plants tissue [18]. However, the scope of infrared photoacoustic spectroscopy to assess nitrogen nutrition levels in rice production remains unexplored.

In rice, the accumulation and distribution of nitrogen in vegetative organs and reproductive organs is an important factor in determining yield. The key period for rice to absorb nitrogen is from tillering to flowering stage, and the absorbed nitrogen is mainly stored in the leaves [22]. At the filling stage, the grain requires a large amount of nitrogen. The amount of nitrogen absorbed by the plant is much smaller than the amount of nitrogen accumulated in the mature grain, and most of the grain nitrogen is transferred from the vegetative organs, especially the leaves [23]. It was reported that a major proportion of nitrogen was redistributed from vegetative organs to panicles at grain filling stage, of which $64 \%$ was from leaf blades, $16 \%$ from leaf sheaths and $20 \%$ from stems [24]. Norman reported that at least $40 \mathrm{~kg}$ of $\mathrm{N}$ per hectare of soil was absorbed between flowering and maturity. The nitrogen content of vegetative parts decreased significantly during flowering and maturity, suggesting that the active nitrogen had been transported to the grains [25]. Considering that the leaf was the main storage organ for nitrogen, and about $65 \%$ of the above-ground nitrogen was located in the green leaf blades [26], thus, the nitrogen content of the leaves can be used to assess the nitrogen nutrition status in rice.

Amides are major chemical structures for nitrogen storage in plants [27, 28], and are classified as either amide I or amide II. The amide I band occurred in the range of 1680 to $1630 \mathrm{~cm}^{-1}$ mainly because of the $\mathrm{C}=\mathrm{O}$ vibrational stretching [29], while the amide II band lies within the range of 1570 to $1510 \mathrm{~cm}^{-1}$ mainly corresponded to the $\mathrm{C}-\mathrm{N}$ stretching vibrations and $\mathrm{N}-\mathrm{H}$ deformation vibrations. In plants, normal nitrogen metabolism initially involves conversion of absorbed nitrates into ammonium ions $\left(\mathrm{NH}_{4}{ }^{+}\right)$, which are then used to synthesize amino acids and other macromolecules. Nevertheless, even low concentrations of $\mathrm{NH}_{4}{ }^{+}$in plants can be very harmful. Hence, plant tissues synthesize glutamine to utilize any $\mathrm{NH}_{4}{ }^{+}$present, thereby, preventing ammonium ion toxicity through glutamate synthase activity. Related research shows that the primary and secondary amides are the dominant forms of nitrogen in plants [27]. Further, an equilibrium between amide II and amide I is reached at a specific nitrogen status. This equilibrium might be altered through transformation between amide I and amide II when the nitrogen supply status changes, thus providing a potential tool for the diagnosis of plant nitrogen status. In this study, we conducted a 4-year field experiment to establish a method involving amide I and amide II of rice leaves based on FTIR-PAS, which can be used for rapid monitoring of the nitrogen status in rice plants.

\section{Methods \\ Experimental locations}

Two field experiments were conducted from 2015 to 2018 at the Tangquan (field experiment 1 ) and Jiangning (field experiment 2) experimental stations of the Nanjing Institute of Soil Science, Chinese Academy of Sciences, Jiangsu province, China (N 32 $04^{\prime} 15^{\prime \prime}$, E $118^{\circ} 28^{\prime} 21^{\prime \prime}$ and $\mathrm{N} 31^{\circ} 48^{\prime} 23.62^{\prime \prime}$, E $118^{\circ} 55^{\prime} 54.69^{\prime \prime}$, respectively). The soil types in the two study areas were paddy soil and river silt soil, and the basic soil properties are as following. The soil in experiment 1 (Tangquan): $\mathrm{pH}$ 6.0, soil organic matter $22.26 \mathrm{~g} \mathrm{~kg}^{-1}$, total $\mathrm{N} 1.31 \mathrm{~g} \mathrm{~kg}^{-1}$, Olsen-P $15.41 \mathrm{mg} \mathrm{kg}^{-1}$, $\mathrm{NH}_{4} \mathrm{OAc}-\mathrm{K} 146.4 \mathrm{mg} \mathrm{kg}^{-1}$; the soil in experiment 2 (Jiangning): $\mathrm{pH} 6.8$, soil organic matter $24.65 \mathrm{~g} \mathrm{~kg}^{-1}$, total $\mathrm{N} 1.72 \mathrm{~g} \mathrm{~kg}^{-1}$, Olsen-P $19.50 \mathrm{mg} \mathrm{kg}^{-1}, \mathrm{NH}_{4} \mathrm{OAc}-\mathrm{K}$ $128.5 \mathrm{mg} \mathrm{kg}^{-1}$. Fertilizers used for these two experiments were as follows: compound fertilizer $\left(\mathrm{N}-\mathrm{P}_{2} \mathrm{O}_{5}-\right.$ $\left.\mathrm{K}_{2} \mathrm{O}: 16-8-18\right)$, coated urea ( $\mathrm{N}-42 \%$, ISSAS, China), and urea $(\mathrm{N}-46 \%)$ controlled release fertilizer $\left(\mathrm{N}-\mathrm{P}_{2} \mathrm{O}_{5}-\mathrm{K}_{2} \mathrm{O}\right.$, 30-10-12, ISSAS, China), and urea (N-46\%).

\section{Elemental design}

Three fertilizer treatments were applied at the Tangquan experimental station from 2015 to 2018 (Table 1). (1) CO: control with no fertilizer application; (2) CF (Conventional Fertilization): conventional nitrogen fertilization, $\mathrm{N}\left(240 \mathrm{~kg} \mathrm{ha}^{-1}\right), \mathrm{P}_{2} \mathrm{O}_{5}\left(60 \mathrm{~kg} \mathrm{ha}^{-1}\right)$, and $\mathrm{K}_{2} \mathrm{O}$ $\left(120 \mathrm{~kg} \mathrm{ha}^{-1}\right.$ ) (phosphate and potash fertilizers were used as the basal fertilizers; Nitrogen fertilizer was applied as basal fertilizer, tillering fertilizer and panicle fertilizer with the ratio of 5:2:3); and (3) OF (Optimized Fertilization): mixed application of compound fertilizer; urea and coated urea (slow-release nitrogen accounted for 30\% of total nitrogen applied), and the application rates were set for $\mathrm{N}, \mathrm{P}_{2} \mathrm{O}_{5}$, and $\mathrm{K}_{2} \mathrm{O}$ as that of CF. All fertilizers were applied in artificial broadcasting. Every treatment was designed with four replicates. Each replicate area was $40 \mathrm{~m}^{2}(4 \mathrm{~m} \times 10 \mathrm{~m})$.

In 2015, 2016, and 2017, we used the rice cultivar Nanjing 46, a translucent endosperm japonica rice variety with good taste, high production and resistance to rice stripe disease, and in 2018, the cultivar was Wuyunjing 23 , a lodging resistant japonica rice cultivar [30, 31]. The 35-day-old rice seedlings were transplanted artificially on June 17, 2015; June 25, 2016; June 8, 2017 and June 12, 2018 at a row spacing of $25 \mathrm{~cm}$ and plant spacing of $20 \mathrm{~cm}$. They were harvested on November 24, 2015; November 24, 2016; November 7, 2017 and October 22, 2018, respectively, before measuring the yields. 
Table 1 Cultivars, treatments and fertilizer rate at each station in the experimental years

\begin{tabular}{|c|c|c|c|c|c|c|}
\hline \multirow[t]{2}{*}{ Experimental station } & \multirow[t]{2}{*}{ Seasons } & \multirow[t]{2}{*}{ Cultivars } & \multirow[t]{2}{*}{ Treatments } & \multicolumn{3}{|c|}{ Fertilizer rate $\left(\mathrm{kg} \mathrm{ha}^{-1}\right)$} \\
\hline & & & & $\mathrm{N}$ & $\mathrm{P}_{2} \mathrm{O}_{5}$ & $\mathrm{~K}_{2} \mathrm{O}$ \\
\hline \multirow[t]{12}{*}{ Tangquan } & & & $\mathrm{CO}$ & - & - & - \\
\hline & 2015 & Nanjing 46 & CF & 240 & 60 & 120 \\
\hline & & & OF & 240 & 60 & 120 \\
\hline & & & $\mathrm{CO}$ & - & - & - \\
\hline & 2016 & Nanjing 46 & $C F$ & 240 & 60 & 120 \\
\hline & & & OF & 240 & 60 & 120 \\
\hline & & & $\mathrm{CO}$ & - & - & - \\
\hline & 2017 & Nanjing 46 & $\mathrm{CF}$ & 240 & 60 & 120 \\
\hline & & & OF & 240 & 60 & 120 \\
\hline & & & $\mathrm{CO}$ & - & - & - \\
\hline & 2018 & Wuyunjing 23 & CF & 240 & 60 & 120 \\
\hline & & & OF & 240 & 60 & 120 \\
\hline \multirow[t]{3}{*}{ Jiangning } & & & $\mathrm{CO}$ & - & - & - \\
\hline & 2018 & Nanjing 5055 & $C F$ & 255 & 64 & 76.5 \\
\hline & & & OF & 192 & 64 & 76.5 \\
\hline
\end{tabular}

Three fertilizer treatments were conducted at the Jiangning experimental station in 2018 (Table 1). (1) CO: control with no fertilization application; (2) CF (Conventional Fertilization): the nutrient application rates were $\mathrm{N}$ $\left(255 \mathrm{~kg} \mathrm{ha}^{-1}\right), \mathrm{P}_{2} \mathrm{O}_{5}\left(64 \mathrm{~kg} \mathrm{ha}^{-1}\right)$, and $\mathrm{K}_{2} \mathrm{O}\left(76.5 \mathrm{~kg} \mathrm{ha}^{-1}\right)$. Controlled release fertilizer was used as the basal fertilizer with a top dressing of urea. Nitrogen fertilizer was applied as basal fertilizer, tillering fertilizer and panicle fertilizer with the ratio of 7.5: 1.5: 1; and (3) OF (Optimized Fertilization): the nutrient application rates were $\mathrm{N}$ (192 kg ha $\left.{ }^{-1}\right), \mathrm{P}_{2} \mathrm{O}_{5}\left(64 \mathrm{~kg} \mathrm{ha}^{-1}\right)$, and $\mathrm{K}_{2} \mathrm{O}\left(76.5 \mathrm{~kg} \mathrm{ha}^{-1}\right)$. Controlled release fertilizer was used as the basal fertilizer. Every treatment was designed with four replicates. Each plot area was $800 \mathrm{~m}^{2}(8 \mathrm{~m} \times 100 \mathrm{~m})$.

We used the japonica rice cultivar Nanjing 5055 with strong resistance to diseases such as stripe disease, rice smut and sheath blight. The 20-day-old rice seedlings were transplanted by machine on June 16, 2018 at a row spacing of $18 \mathrm{~cm}$ and plant spacing of $10 \mathrm{~cm}$. They were harvested on November 9, 2018, and the yield was measured.

\section{Sampling and laboratory procedures for all experiments}

In experiment 1 , the leaf samples were collected at tillering, jointing, full panicle and mature growth stages from each experimental plot in the 2015 rice season. In 2016, 2017, and 2018, leaf samples were collected at mature growth stages only. In experiment 2 , the leaf samples were collected only at mature growth stage. All plant samples were oven-dried at $105{ }^{\circ} \mathrm{C}$ for $30 \mathrm{~min}$ and then at $60{ }^{\circ} \mathrm{C}$ for 2 days. They were then ground for photoacoustic spectral recording and total $\mathrm{N}$ determination. The total nitrogen concentration of leaf samples was determined using a SmartChem 200 discrete auto analyzer (AMS Alliance, Frepillon, France).

\section{Photoacoustic spectra recording}

A FTIR Nicolet 6700 spectrometer (Thermo Electron Scientific Instruments Corporation, Madison, WI, USA) with a model 300 photoacoustic cell (MTEC Photoacoustics, Inc., Oakland, California, USA) was used to record FTIR spectrum of leaf samples. An appropriate amount of ground samples was placed in the photoacoustic cup for direct determination in the infrared photoacoustic spectrum. Before the determination was made, helium was purged for $20 \mathrm{~s}$ to reduce the infrared absorption interference from carbon dioxide and water in the air [18]. Scans were conducted in the wavenumber range of 4000 to $500 \mathrm{~cm}^{-1}$, the mirror speed was set to $0.32 \mathrm{~cm} \mathrm{~s}^{-1}$, and the resolution was $4 \mathrm{~cm}^{-1}$. Each sample was scanned 32 times in succession.

\section{Data processing}

The FTIR-PAS rice spectra were smoothed to reduce noise using the Savitzky-Golay filter [12, 32]. Principal component analysis (PCA) is a multivariate statistical analysis method in which multiple variables are linearly transformed to select fewer important variables [33]. Deconvolution was used to separate the comprehensive information among the spectrum $[34,35]$. The objective of deconvolution curve fitting was to separate each peak, which may contain many independent peaks. 
The principle are as follows:

$$
Y(x)=\Sigma F i(x)
$$

where $Y, x$, and $i(1,2,3, \ldots n)$ represent the spectrum, wavenumber and number of isolated peak, respectively, the $F$ is the expansion function or the kernel function of deconvolution. The Gauss function used was:

$$
y=\frac{a_{0}}{\pi \sqrt{\pi a_{2}}} \exp \left[-\frac{1}{2}\left(\frac{x-a_{1}}{a_{2}}\right)^{2}\right]
$$

where $a_{0}, a_{1}$, and $a_{2}$ represent the peak amplitude, position, and width, respectively, while $x$ and $y$ are the wavenumber and photoacoustic intensity respectively.

Preprocessing of photoacoustic spectra and PCA were performed in Matlab R2016a (The MathWorks, Natick, MA, USA). Curvefitting was conducted using Peakfit 4.12. Analysis of variance (ANOVA) was performed using SPSS 19.0 for Windows (SPSS Inc., Chicago, IL, USA).

\section{Results}

Mid-infrared photoacoustic spectra of leaves

The photoacoustic spectra of rice leaves from tillering, jointing, full panicle and mature stages with different treatments in 2015 are shown in Fig. 1, and the photoacoustic spectra of rice leaves in 2016, 2017 and 2018 can be obtained from additional file (Additional file 1: Figure S1).

The total spectral shapes and typical bands for all the treatments were similar among the different growth stages. The peak seen at approximately $3365 \mathrm{~cm}^{-1}$ was associated with $\mathrm{N}-\mathrm{H}$ stretching vibration; the peak at $2925 \mathrm{~cm}^{-1}$ was associated with $\mathrm{C}-\mathrm{H}$ stretching vibration [36]; the peak in the range of 1680 to $1630 \mathrm{~cm}^{-1}$ was associated with stretching vibration of $\mathrm{C}=\mathrm{O}$ from amide I, and a small shoulder peak in the range of 1570 to $1510 \mathrm{~cm}^{-1}$ was associated with amide II. Spectral intensities of these two bands varied but the band position unchanged. Besides, the fingerprint around $1060 \mathrm{~cm}^{-1}$ was caused by $\mathrm{C}-\mathrm{O}$ stretching vibration. Despite the spectral intensity changes in the wavenumber range of
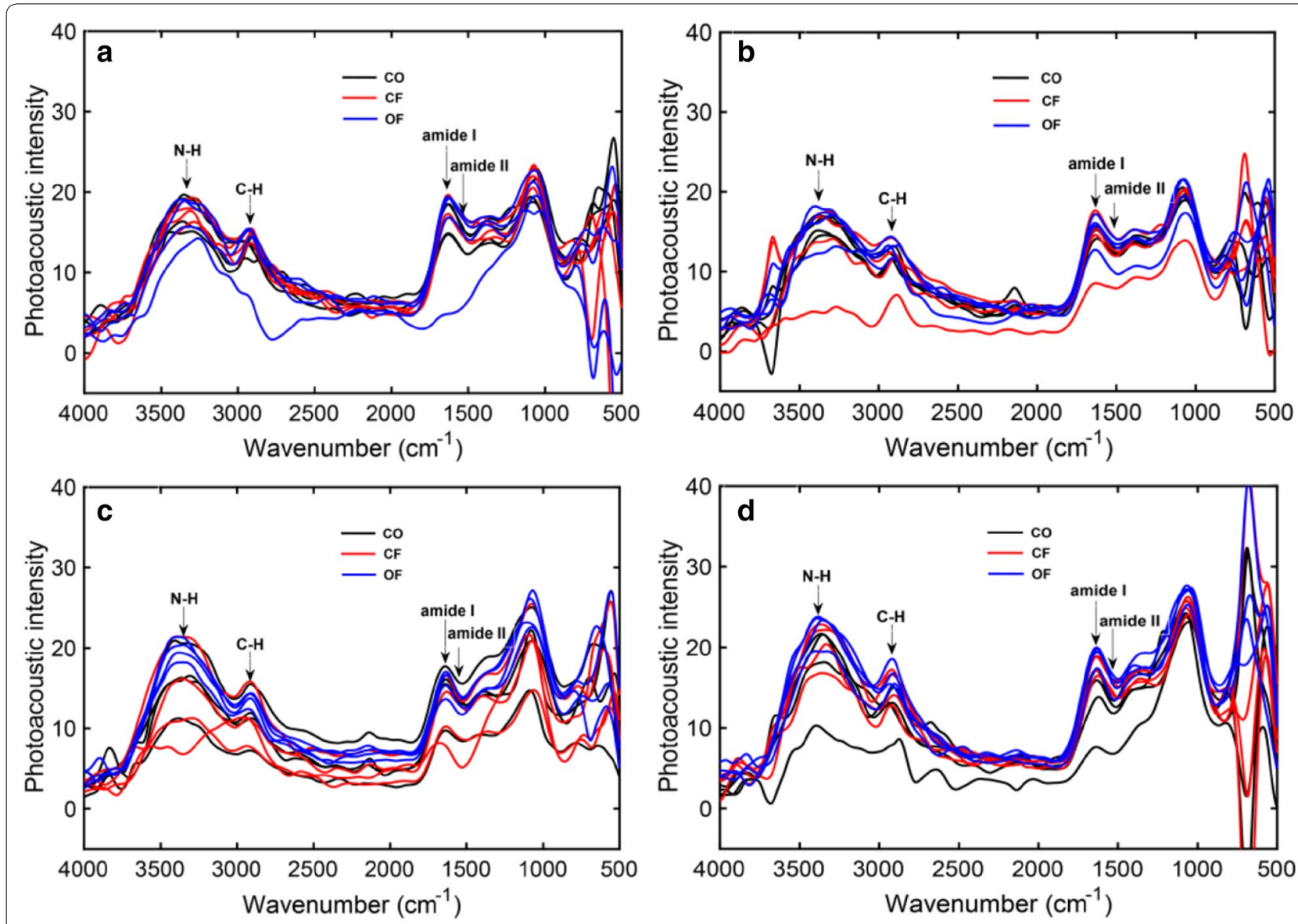

Fig. 1 FTIR-PAS of leaves from different Rice stages with different treatments in 2015 growth season. a Tillering stage, $\mathbf{b}$ jointing stage, $\mathbf{c}$ full panicle stage, $\mathbf{d}$ mature stage 
$1570-1510 \mathrm{~cm}^{-1}$ and $1680-1630 \mathrm{~cm}^{-1}$, the change laws among the different stages and treatments were not found. Further, the principal component analysis (PCA) based on photoacoustic spectra of Rice leaves at the growth stages with different treatments was conducted. However, at each growth stage, the score plot exhibited an irregular pattern among the different treatments (Additional file 1: Figure S2). According to some studies, the full spectrum might contain a lot of disturbed information interferences, which could reduce prediction capacity, robustness, and accuracy [37-39]. Hence, PCA distribution with full spectral range is not appropriate for the assessment of nitrogen status of rice. Therefore, specific wavelength range and other algorithms were considered for achieving the target diagnosis.

\section{Curve-fitting through deconvolution}

Two peaks indicative of amide among the four growth stages with different treatments in 2015 are shown in Fig. 2. The correlation coefficients $\left(R^{2}\right)$ between original and fitted spectra were above 0.8 and standard deviations were less than 1 . Two peaks appear almost in the same spectral band of different treatments. The first peak related to amide I was at $1680-1630 \mathrm{~cm}^{-1}$ and the second peak was nearly at $1570-1510 \mathrm{~cm}^{-1}$. Thus, two independent peaks were formed, the former by the stretching vibration of the $\mathrm{C}=\mathrm{O}$ from amide $\mathrm{I}$ and the lateral by the stretching vibration of $\mathrm{C}-\mathrm{N}$ and the deformation vibration of $\mathrm{N}-\mathrm{H}$ from amide II $[29,40]$.

The bands representing amide I and amide II, despite showing approximately similar positions among the different growth stages and treatments, differed in absorption intensity. Amide has been proved to be the main chemical form for Nitrogen storage in plants. Therefore, it was presumed that these two absorption bands could be assessed for nitrogen status in rice. These two peaks were subjected to peak-fitting to find out possible relevance among the growth stages and different treatments. The effect of peak-fitting was determined by the correlation coefficient between fitted and original spectra, and the standard deviation. The higher correlation coefficient $\left(\mathrm{R}^{2}\right)$ resulted in smaller standard deviation as well as better effect of peak-fitting. The deconvolution curve-fitting in 2016, 2017, and 2018 appeared in Additional file 1: Figure S3.

\section{Diagnosis of nitrogen status in rice}

As shown in Table 2, the yield of CO treatment was significantly lower than the other two treatments indicating that no nitrogen supply caused a low yield. In comparison with CF treatment, OF treatment showed a higher yield with an increment of $4.0 \%-7.8 \%$. There were significant differences between $\mathrm{CO}$ and the other two treatments on total nitrogen concentration in rice leaves at the four growth stages in 2015 growth season, whereas no difference was found between CF and OF treatments (Table 3). However, the total nitrogen at mature stage was far less than the other three growth stages, implying that the nitrogen transportation occurred in the growth stages. Besides, for the mature stage from 2016, 2017 and 2018 growth seasons, the differences between $\mathrm{CO}$ and the other two treatments on total nitrogen concentration in rice leaves were also significant, whereas there were no significant differences between CF and OF treatments, implying that fertilization can significantly increase the rice leaves nitrogen concentration.

In the spectrum, the intensity of spectral absorption was usually interfered by the instrument and external environment [18]. Therefore, the ratio of photoacoustic intensity of amide II to amide I in rice leaves was recorded to avoid this interference (Fig. 3). In 2015 growth season, the ratios of photoacoustic intensity of amide II to amide I in rice leaves sampled in CF and OF treatments were significantly higher than the ratio of $\mathrm{CO}$ treatment (Fig. 3a). At tillering stage, the ratioof $\mathrm{CO}$ treatment showed a minimal value of 0.21 , however, the same ratio reached 0.43 and 0.48 when $C F$ and $O F$ treatments were used, respectively. Subsequently, at the Jointing stage, the ratio reached 0.49 , which was higher than that of $\mathrm{CO}$ and $\mathrm{CF}$ treatments. At full panicle stage, the ratio of OF treatment was still at a high level $(0.48)$ due to the continuously release nitrogen nutrition from coated urea, whereas the ratio reached 0.55 when CF treatment was used, because of the top dressing fertilization with urea, thus providing sufficient nitrogen nutrition for rice, resulting in a higher content of nitrogen in the sampled leaves. The ratio decreased at the mature stage compared to that at the full panicle stage regardless of the treatment used. Related research shows that the primary and secondary amides are the dominant forms of nitrogen in plants [27]. When supplied with excess nitrogen, extra nitrogen was transformed into secondary amides, therefore, In $\mathrm{CO}$, with no-nitrogen supply, the ratio (approximately 0.2 ) was much lower than in CF or OF. At the later growth stages, the grain absorbs nearly $80 \%$ of the nitrogen found especially in leaves and in stems [24]. Thus, two-thirds of the nitrogen in stems and leaves was transported to the ears for grain filling [41]. Due to the application of coated urea $\left(\mathrm{CO}\left(\mathrm{NH}_{2}\right)_{2}\right)$ at the first three stages, the ratio in OF was relatively stable (above 0.48 ), that is, the ability of the slow-releasing coated urea to supply nitrogen to the plants was relatively long lasting.

Overall, increased nitrogen accumulation in stems and leaves led to increased nitrogen transportation for grain filling and thereby increased the yield [42, 43]. Therefore, the nitrogen status of the leaves can 

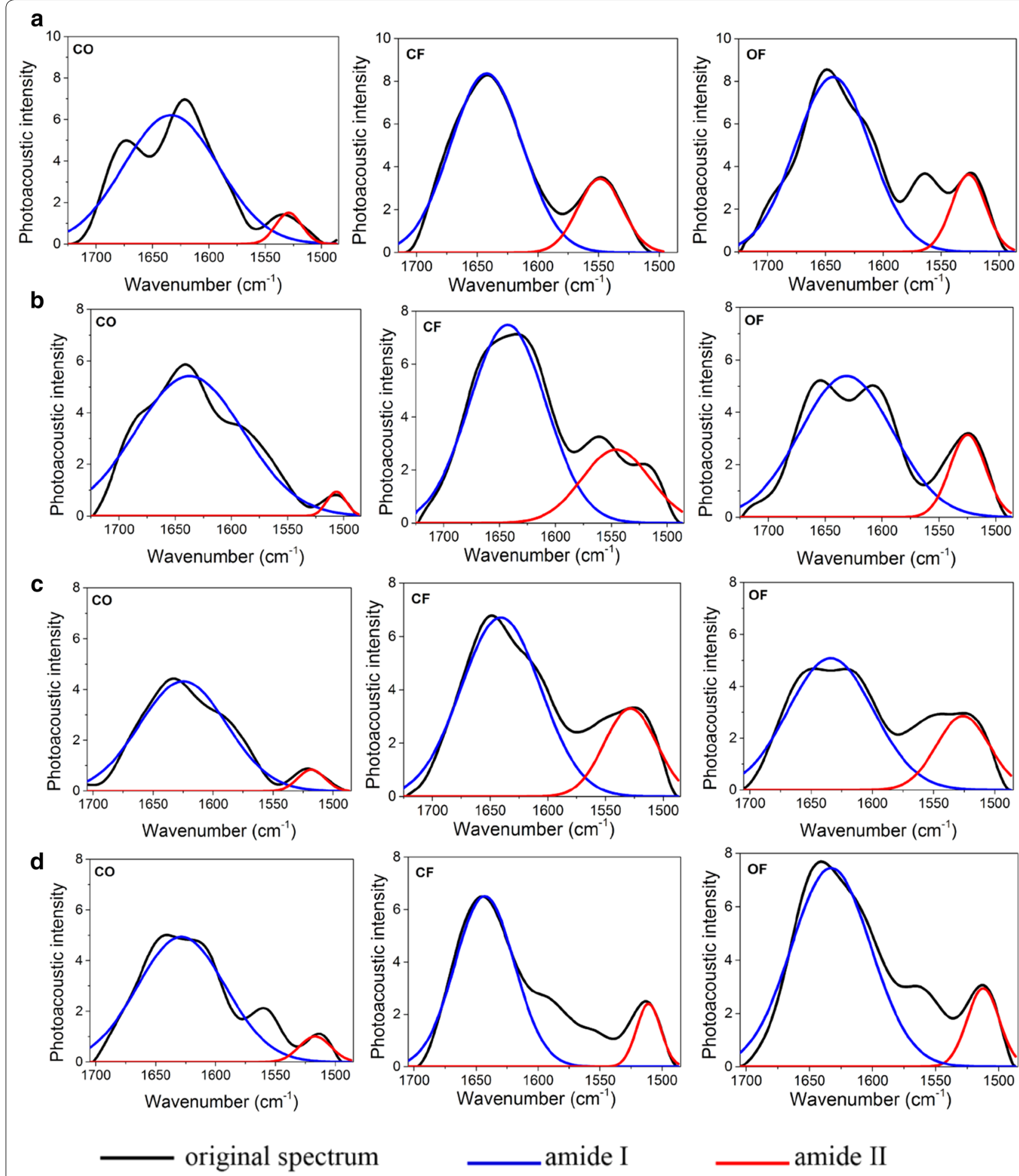

amide I

amide II

Fig. 2 Deconvolution Curve-fitting with different treatments at four stages in 2015 growth season. a Tillering stage, b jointing stage, c full panicle stage, $\mathbf{d}$ mature stage; CO control with no fertilization application, CF conventional fertilization, OF optimized fertilization 
Table 2 Effect of $\mathbf{N}$ application on rice yield with different treatments in different growth seasons

\begin{tabular}{|c|c|c|c|c|}
\hline \multirow[t]{2}{*}{ Experimental station } & \multirow[t]{2}{*}{ Seasons } & \multicolumn{3}{|c|}{ Rice yield $\left(\mathrm{kg} \mathrm{ha}^{-1}\right)$} \\
\hline & & $\mathrm{CO}$ & $\mathrm{CF}$ & OF \\
\hline \multirow[t]{4}{*}{ Tangquan } & 2015 & $7575 \pm 282.2^{b}$ & $9432 \pm 345.6^{a}$ & $9872 \pm 297.5^{a}$ \\
\hline & 2016 & $6385 \pm 255.5^{b}$ & $8633 \pm 246.3^{\mathrm{a}}$ & $9155 \pm 392.5^{a}$ \\
\hline & 2017 & $4095 \pm 195.7^{b}$ & $5844 \pm 246.8^{a}$ & $6297 \pm 268.5^{a}$ \\
\hline & 2018 & $6887 \pm 323.7^{b}$ & $8925 \pm 267.5^{a}$ & $9375 \pm 422.9^{a}$ \\
\hline Jiangning & 2018 & $7212 \pm 258.6^{b}$ & $11077 \pm 532.7^{\mathrm{a}}$ & $11515 \pm 478.7^{\mathrm{a}}$ \\
\hline
\end{tabular}

Data are expressed as the means of four replications. Significant differences $(P \leq 0.05)$ among treatments within each line are indicated with different letters

Table 3 Effect of $\mathbf{N}$ application on total $\mathbf{N}$ concentration of rice leaves with different treatments in different growth seasons

\begin{tabular}{|c|c|c|c|c|c|c|}
\hline \multirow[t]{2}{*}{ Experimental station } & \multirow[t]{2}{*}{ Seasons } & \multirow[t]{2}{*}{ Treatments } & \multicolumn{4}{|l|}{ Total $\mathbf{N}\left(\mathrm{g} \mathrm{kg}^{-1}\right)$} \\
\hline & & & Tillering stage & Jointing stage & Panicle stage & Mature stage \\
\hline \multirow[t]{12}{*}{ Tangquan } & & $\mathrm{CO}$ & $10.58 \pm 0.52^{b}$ & $9.95 \pm 0.37^{b}$ & $10.52 \pm 0.55^{b}$ & $9.97 \pm 0.47^{b}$ \\
\hline & 2015 & CF & $24.98 \pm 0.75^{\mathrm{a}}$ & $22.00 \pm 0.59^{a}$ & $29.11 \pm 0.77^{a}$ & $12.45 \pm 0.35^{\mathrm{a}}$ \\
\hline & & OF & $28.65 \pm 0.68^{\mathrm{a}}$ & $26.61 \pm 0.85^{a}$ & $25.13 \pm 0.65^{a}$ & $12.05 \pm 0.38^{\mathrm{a}}$ \\
\hline & & $\mathrm{CO}$ & - & - & - & $10.49 \pm 0.20^{b}$ \\
\hline & 2016 & $\mathrm{CF}$ & - & - & - & $12.31 \pm 0.30^{\mathrm{a}}$ \\
\hline & & OF & - & - & - & $12.40 \pm 0.55^{\mathrm{a}}$ \\
\hline & & $\mathrm{CO}$ & - & - & - & $10.23 \pm 0.26^{b}$ \\
\hline & 2017 & $\mathrm{CF}$ & - & - & - & $11.87 \pm 0.65^{\mathrm{a}}$ \\
\hline & & OF & - & - & - & $11.90 \pm 0.46^{\mathrm{a}}$ \\
\hline & & $\mathrm{CO}$ & - & - & - & $9.86 \pm 0.0 .57^{b}$ \\
\hline & 2018 & $\mathrm{CF}$ & - & - & - & $11.81 \pm 0.44^{\mathrm{a}}$ \\
\hline & & OF & - & - & - & $11.09 \pm 0.25$ \\
\hline \multirow[t]{3}{*}{ Jiangning } & 2018 & $\mathrm{CO}$ & - & - & - & $9.51 \pm 0.32^{b}$ \\
\hline & & $\mathrm{CF}$ & - & - & - & $11.28 \pm 0.36^{a}$ \\
\hline & & OF & - & - & - & $10.68 \pm 0.35^{\mathrm{a}}$ \\
\hline
\end{tabular}

Data are expressed as the means of four replications. Significant differences $(P \leq 0.05)$ among treatments within each column are indicated with different letters

be used to characterize the nitrogen nutritional status of rice. In addition, at the first three growth stages in 2015, the total nitrogen concentration of leaves showed a positively linear correlation $\left(R^{2}=0.97\right)$ with the intensity ratio of amide II to amide I (Fig. 4a). In 2015, 2016, 2017 and 2018 mature stages, the ratio of CO was significantly lower than the ratio of CF and OF treatments. For all treatments, the ratios were below 0.3 (Fig. 3b) and displayed relatively low relevance $\left(R^{2}=0.35\right)$ between the ratio and total nitrogen concentration (Fig. 4b). Besides, for the maturity from every growth season, the correlation still remained relatively low (Additional file 1: Figure S4), which can probably be due to the fact that only mature leaf samples were measured. However, in 2015 growth season, the $\mathrm{R}^{2}$ was 0.94 (Fig. 4c), while for all the growth seasons, the $\mathrm{R}^{2}$ reached 0.9 (Fig. 4d), implying a good correlation between the total $\mathrm{N}$ and the ratio. Therefore, our results suggest that the intensity ratio of amide II to amide I can reflect the total $\mathrm{N}$ of the rice leaves well through the growth stages.

Since tillering and grouting play an important role in rice yield $[22,44]$. Thus, the ratio at the tillering and full panicle stages were more suitable for diagnosis. At these two stages, the ratios of $\mathrm{CF}$ and OF treatments were above 0.4 , moreover, at full panicle stage, the ratio of $\mathrm{CF}$ treatment reached 0.55; whereas the ratios of $\mathrm{CO}$ (with no fertilization) were around 0.2 . Therefore, taking into account the level and stages of nitrogen supply among the different treatments, the intensity ratio of amide II to 

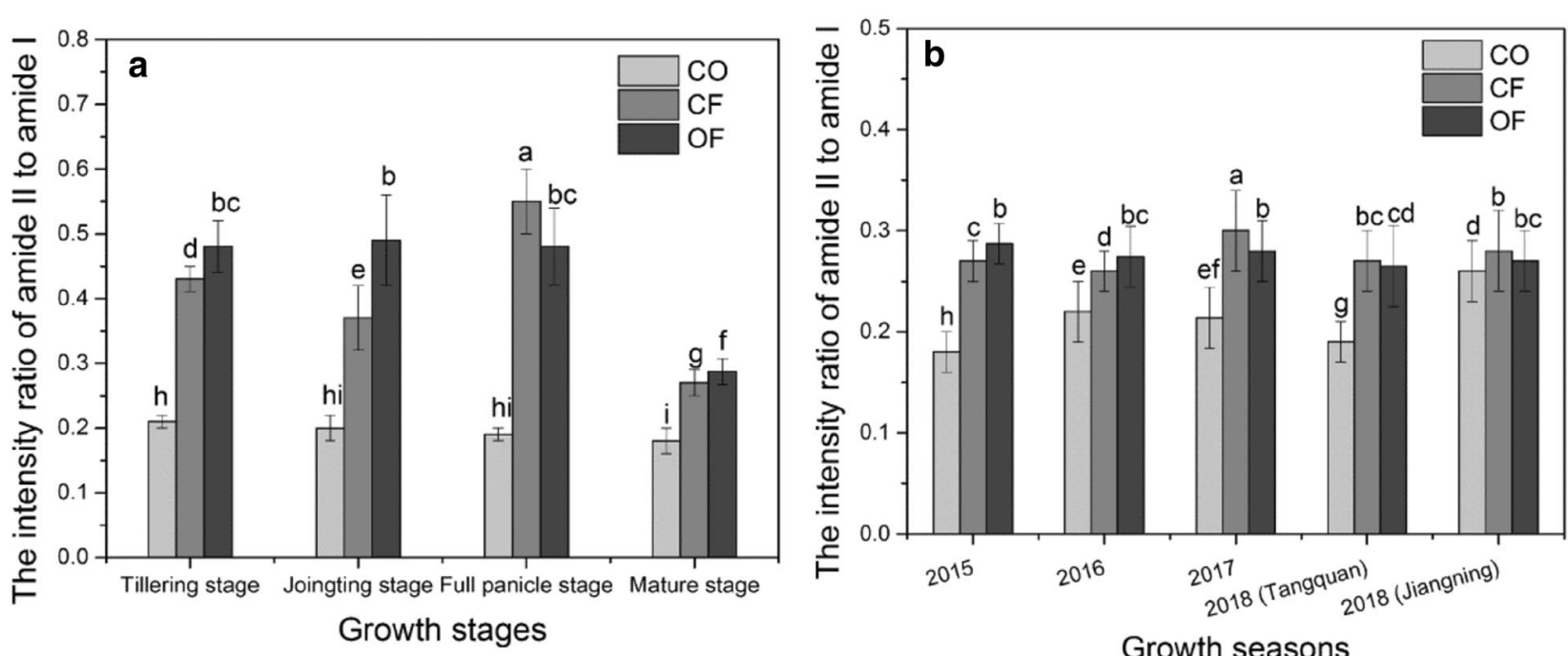

Fig. 3 The photoacoustic intensity ratio of amide II to amide I. CO Control with no fertilization application, CF Conventional Fertilization, OF Optimized Fertilization. a The ratio of amide II to amide I in different treatments at four growth stages in the 2015 growth season, $\mathbf{b}$ the ratio of amide II to amide I in different treatments at mature stage in the 2015, 2016, 2017 and 2018 growth seasons. Bars are the standard error of the means. Different letters above the bars indicate a significant difference at $\mathrm{P}<0.05$ according to the Duncan test

amide I in rice leaves, and combined with the rice yield, a ratio of $0.4-0.55$ reflects a suitable plant nitrogen status. When the ratio is less than 0.4 , nitrogen content in the plant leaf tissues can be considered insufficient, while a ratio above 0.55 implies excess nitrogen in the plant tissues.

\section{Discussion}

Our study shows that the correlation between the intensity ratio and rice leaves total Nitrogen concentration was relatively high with a coefficient of 0.94 throughout the 2015 growth season (Fig. 4c). However, the correlation coefficient $\left(R^{2}\right)$ at mature stage from 2015, 2016, 2017 and 2018 growth seasons was only 0.36 (Fig. 4b), similarly, the correlations were also not relatively high for the mature stage from every growth season (Additional file 1: Figure S4). This is mainly due to the fact that the total N concentration and ratio in leaves at mature stage were relatively low, and the variations of total $\mathrm{N}$ concentration and ratio were slighter compared with the calculation throughout the growth season, thus resulting in a relatively not high correlation. Besides, for the mature stage from all growth seasons, the ratios were below 0.3 among different treatments.

In 2018, at Jiangning station, the ratio of $\mathrm{CO}$ was very close to the ratios of $\mathrm{CF}$ and $\mathrm{OF}$, implying that the ratio was poorly respond to the Nitrogen supply. Therefore, the ratio at the mature stage was not suitable for nitrogen diagnosis. Meanwhile, according to the analysis of all data samples in four growth seasons, the intensity ratio of amide II to amide I and the total Nitrogen concentration still showed a high correlation (Fig. 4d). This still indicates that during the entire growth period of Rice, the ratio can be used to assess the Nitrogen levels. In our study, at the tillering and full panicle stages, a ratio of 0.4-0.55 was considered appropriate. However, for Chinese cabbage, the ratio of $0.9-1.0$ was suitable for its growth and without massive Nitrate accumulation [18], indicating that the appropriate ratio depends on the plant species. In addition, in our field experiments, we used three rice cultivars, whether this ratio is applicable to all rice cultivars is still unknown. Therefore, more cultivars need to be studied in future to increase the scope of this experiment.

\section{Conclusions}

According to the FTIR-PAS of rice leaves, the ratio of photoacoustic intensity of amide II to amide I was positively correlated to different nitrogen treatments and growth stages, and the ratios at tillering and full panicle stages were more suitable for nitrogen diagnosis. A ratio of $0.4-0.55$ likely reflects a suitable nitrogen status for rice. For a ratio less than 0.4, the nitrogen status can be considered insufficient, whereas a ratio above 0.55 

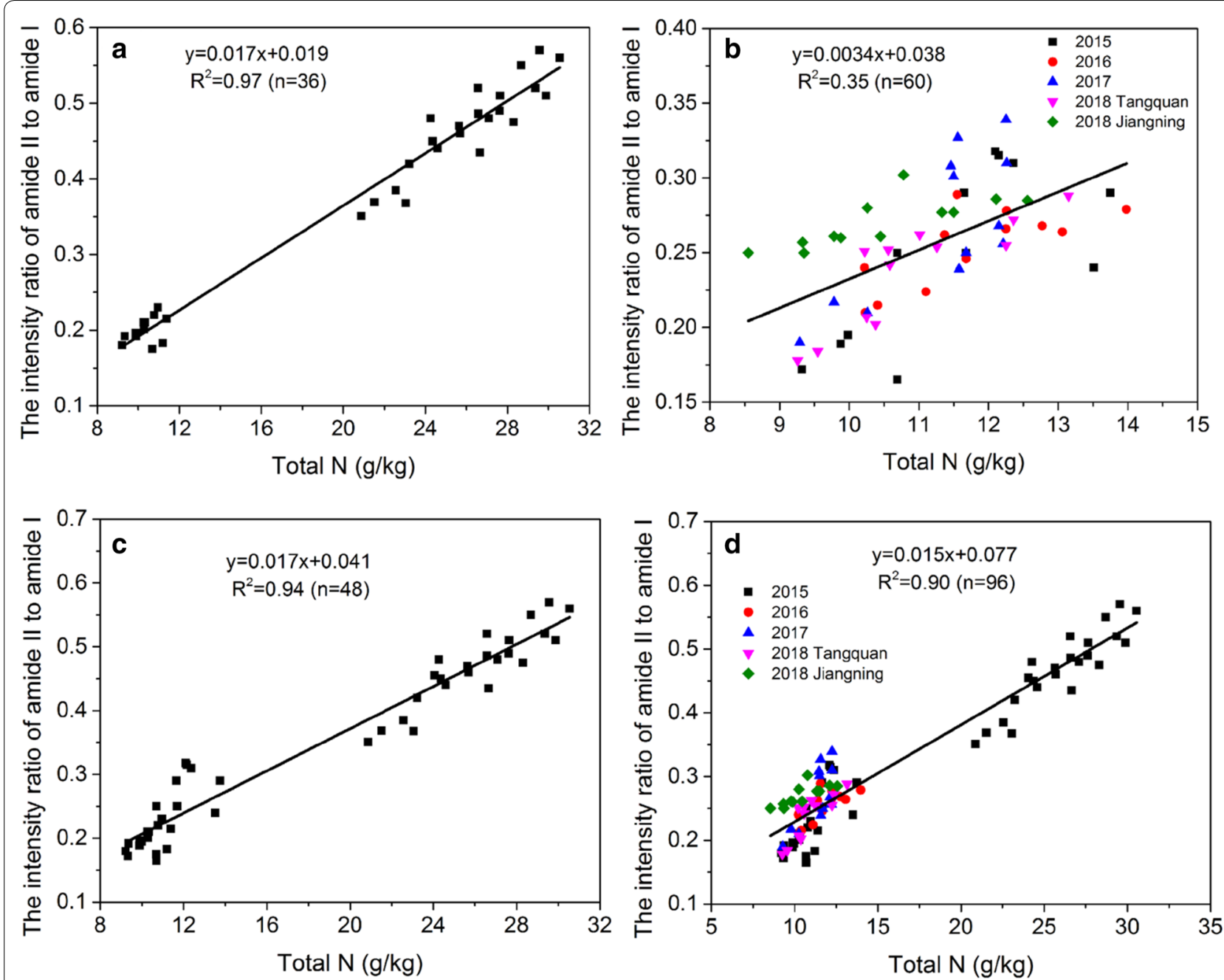

Fig. 4 Linear regression between the total N concentration of rice leaves and the ratio of amide II to amide I. a The 2015 growth season for the first three stages only excluding the mature stage. b Only at the maturity from all growth seasons. c All growth stages in the 2015 season. d 2015, 2016, 2017 and 2018 growth seasons. The linear functions and the square of the Correlation Coefficient $\left(R^{2}\right)$ are shown in the each plot

implies excess nitrogen. Thus, by using the FTIR-PAS, we can facilitate effective assessment of the nitrogen status in rice production, which can provide appropriate guidance for rational fertilization.

\section{Additional file}

Additional file 1. Additional figures.

\section{Acknowledgements}

Not applicable.

\section{Authors' contributions}

CWD and JMZ designed and directed the experiments. KW conducted the experiments and recorded the spectra data. KW, DL, YZS and FM were involved in the data analysis. KW composed the initial manuscript, and CWD made a revision. All authors read and approved the final manuscript.

\section{Funding}

This work was supported by the National Key Basic Research Program of China (2015CB150403), the Key Research and Development Program of Jiangsu Province China (BE2017388) and the "STS" project from Chinese Academy of Sciences (KFJ-STS-QYZX-046, KFJ-PTXM-003).

\section{Availability of data and materials}

The datasets supporting the conclusion of this article are included within the article (additional files).

Ethics approval and consent to participate

Not applicable.

\section{Consent for publication}

Not applicable.

\section{Competing interests}

The authors declare that they have no competing interests. 


\section{Author details}

${ }^{1}$ The State Key Laboratory of Soil and Sustainable Agriculture, Institute of Soil Science, Chinese Academy of Sciences, Nanjing 210008, China. ${ }^{2}$ University of Chinese Academy of Sciences, Beijing 100049, China.

Received: 11 June 2019 Accepted: 10 August 2019 Published online: 19 August 2019

\section{References}

1. Xue YG, Yang JC. Physiological characteristics and cultivation techniques for super-high -yield Rice. Crops. 2009;6:8-12.

2. Kraiser T, Gras DE, Gutiérrez AG, González B, Gutiérrez RA. A holistic view of nitrogen acquisition in plants. J Exp Bot. 2011;62:1455-66.

3. McAllister $\mathrm{CH}$, Beatty PH, Good AG. Engineering nitrogen use efficient crop plants: the current status. J Plant Biotech. 2012;10:1011-25.

4. Huang JL, He F, Cui KH, Burech RJ, Xu B, Guang WH, Peng SB. Determination of optimal nitrogen rate for rice varieties using a chlorophyll meter. Field Crops Res. 2008;105:70-80.

5. Schepers JS, Moravek MG, Alberts EE, Frank KD. Maize production impacts on ground water quality. J Environ Qual. 1991;20:12-6.

6. Jia FF, Liu GS, Liu DS, Zhang YY, Fan WG, Xing XX. Comparison of different methods for estimating nitrogen concentration in flue-cured tobacco leaves based on hyper- spectral reflectance. Field Crops Res. 2013;150:108-14.

7. Wang Y, Wang DJ, Shi PH, Omass K. Estimating rice chlorophyll content and leaf nitrogen concentration with a digital still color camera under natural light. Plant Methods. 2014;10:1-11.

8. Munoz-Huerta RF, Guevara-Gonzalez RG, Contreras-Medina LM, TorresPacheco I, Prado-Olivarez J, Ocampo-Velazquez RV. A review of methods for sensing the nitrogen status in plants advantages, disadvantages and recent advances. Sensors. 2013;13:10823-43.

9. Zhu Y, Yao X, Tian YC, Liu XJ, Cao WX. Analysis of common canopy vegetation indices for indicating leaf nitrogen accumulation in wheat and rice. Int J Appl Earth Obs Geoinform. 2008;10:1-10.

10. Stone ML, Solie JB, Raun WB. Use of spectral radiance for correcting in season fertilizer nitrogen deficiencies in winter wheat. Trans ASAE. 1996;39:1623-31.

11. Tarpley L, Reddy KR, Gretchen FSC. Reflectance indices with precision and accuracy in predicting cotton leaf nitrogen concentration. Crop Sci. 2000;40:1814-9.

12. Du CW, Zhou JM, Wang HY, Chen $X Q$, Zhang AN, Zhang JB. Determination of soil properties using Fourier transform mid-infrared photoacoustic spectroscopy. Vib Spectros. 2009;49:32-7.

13. Xing Z, Du CW, Tian K, Ma F, Shen YZ, Zhou JM. Application of FTIR-PAS and Raman spectroscopies for the determination of organic matter in farmland soils. Talanta. 2016;158:262-9.

14. Andrade LHC, Freitas PG, Mantovani BG, Figueiredo MS, Lima RA, Lima SM, Rangel MAS, Mussury RM. Detection of soybean rust contamination in soy leaves by FTIR photoacoustic spectroscopy. Eur Phys J Spectros Top. 2008;153:539-41.

15. Wang J, Wang H. Ammonia, carbon dioxide and water vapor detection based on tunable fiber laser photoacoustic spectroscopy. Optik. 2016;127:942-5.

16. Doka O, Bicanic $D$, Szollosy L. Rapid and gross screening for $\mathrm{Pb}_{3} \mathrm{O}_{4}$ adulterant in ground sweet red paprika by means of photoacoustic spectroscopy. Instrum Sci Technol. 1998;26:203-8.

17. Yang $\mathrm{H}$, Irudayaraj J. Characterization of beef and pork using Fouriertransform infrared photoacoustic spectroscopy. LWT-Food Sci Technol. 2001;34:402-9.

18. Li CY, Du CW, Ma F, Zhou JM. Diagnosis of nitrogen status in Chinese cabbage (Brassica rapachinensis) using the ratio of amide II to amide I in leaves based on mid-infrared photoacoustic spectroscopy. J Plant Nutr Soil Sci. 2015;178:888-95.

19. Lu YZ, Du C, Yu CB, Zhou JM. Determination of nitrogen in rapeseed by Fourier transform infrared photoacoustic spectroscopy and independent component analysis. Anal Lett. 2015;48:1150-62.

20. Yang JB, Du CW, Shen YZ, Zhou JM. Diagnosis of Chinese cabbage nitrogen nutrition using mid-infrared spectroscopy. J Plant Nutr Fert. 2013;19:1012-7.
21. Rai AK, Singh JP. Perspective of photoacoustic spectroscopy in disease diagnosis of plants. Instrum Sci Technol. 2003;31:323-42.

22. Jiang LG, Dai TB, Jiang D. Characterizing physiological N-use efficiency as influenced by nitrogen management in three rice cultivars. Field Crops Res. 2004;88:239-50.

23. Mae T. Physiological nitrogen efficiency in rice: nitrogen utilization, photosynthesis, and yield potential. Plant Soil. 1997;196:201-10.

24. Mae T, Ohira K. The remobilization of nitrogen related to leaf growth and senescence in rice plants (Oryza sativa L.). Plant Cell Physiol. 1981;22:1067-74.

25. Norman RJ, Guindo D, Wells BR, JrWilson CE. Seasonal accumulation and partitioning of nitrogen-15 in rice. Soil Sci Soc Am J. 1992;56:1521-7.

26. Ladha JK, Kirk GJD, Bennett J, Peng S, Reddy CK, Reddy PM, Singh U. Opportunities for increased nitrogen-use efficiency from improved lowland rice germplasm. Field Crops Res. 1998;56:41-71.

27. Lam HM, Coschigano KT, Oliveira IC, Melo-Oliveira R, Coruzzi GM. The molecular-genetics of nitrogen assimilation into amino acids in higher plants. Annu Rev Plant Phys. 1996:47:569-93.

28. Cao CL, Li SX. Effects of $\mathrm{N}$ form on some physiological characteristics and yield of wheat during the vegetative and reproductive growth stage. Acta Agron Sin. 2003;29:258-62.

29. Kong JL, Yu SN. Fourier transform infrared spectroscopic analysis of protein secondary structures. Acta Bioch Bioph Sin. 2007;39:549-59.

30. Wang CL, Zhang YD, Zhu Z, Chen T, Zhao L, Lin J, Zhou LH. Development of a New Japonica rice variety Nanjing 46 with Good eating quality by marker assisted selection. Mol plant breeding. 2009;7:1070-6.

31. Zhang WJ, Wu LM, Wu XR, Ding YF, Li GH, Li JY, Weng F, Liu ZH, Tang S, Ding CQ, Wang SH. Lodging resistance of japonica rice (Oryza sativa L.): Morphological and anatomical traits due to top-dressing nitrogen application rates. Rice. 2016;9:31.

32. Savitzky A, Golay MJE. Smoothing and differentiation of data by simplified least squares procedures. Anal Chem. 1964:8:1627-39.

33. Abdi H, William LJ. Principal component analysis. Wires Comput Stat. 2010;2:433-59.

34. Buslov DK, Nikonenko NA. Regularized method of spectral curve deconvolution. Appl Spectrosc. 1997;51:666-72.

35. Buslov DK, Nikonenko NA, Sushko NI, Zhbankov RG. Analysis of the structure of the bands in the IR spectrum of $\beta$-D glucose by the regularized method of deconvolution. J Appl Spectrosc. 2002;69:817-24.

36. Lu YZ, Du CW, Yu CB, Zhou JM. Use of FTIR-PAS combined with chemometrics to quantify nutritional information in rapeseeds (Brassica napus). J Plant Nutr Soil Sci. 2014;177:927-33.

37. Jie DF, Xie $\sqcup$, Fu XP, Rao XQ Ying YB. Variable selection for partial least squares analysis of soluble solids content in watermelon using nearinfrared diffuse transmission technique. J Food Eng. 2013;118:387-92.

38. Mehmood T, Liland KH, Snipen L. A review of variable selection methods in partial least squares regression. Chemometr Intell Lab Syst. 2012;1 18:62-9.

39. Wu D, He Y, Nie PC, Cao F, Bao YD. Hybrid variable selection in visible and near-infrared spectral analysis for noninvasive quality determination of grape juice. Anal Chim Acta. 2010;659:229-37.

40. Ami D, Mereghetti P, Natalello A, Doglia SM. Fourier Transform Infrared Microspectroscopy as a Tool for Embryonic Stem Cell Studies. In: Atwood C, editor. Methodological advances in the culture, manipulation and utilization of embryonic stem cells for basic and practical applications. Rijeka: InTech; 2011. p. 193-218.

41. Ntanos DA, Koutroubas SD. Dry matter and N accumulation and translocation for Indica and Japonica rice under Mediterranean conditions. Field Crops Res. 2002;74:93-101.

42. Huo ZY, Yang $X$, Zhang HC, Ge MJ. Accumulation and translocation of dry matter and nitrogen nutrition in organs of rice cultivars with different productivity levels. Plant Nutr Fertilizer Sci. 2012;18:1035-45 (in Chinese)

43. Zhang Y, Wu J, Zhang Y. Genotypic variation of nitrogen accumulation and Translocation in japonica Rice cultivars with different height. J Nanjing Agric Univ. 2006;29:71-4 (in Chinese)

44. Counce PA, Siebenmorgen TJ, Poag MA, Holloway GE, Kocher MF, Lu RF. Panicle emergence of tiller types and grain yield of tiller order for directseeded rice cultivars. Field Crops Res. 1996:47:235-42.

\section{Publisher's Note}

Springer Nature remains neutral with regard to jurisdictional claims in published maps and institutional affiliations. 